\title{
Effect of Adding Nalbuphine Hydrochloride Versus Fentanyl on The Characteristic of Hyperbaric Bupivacaine Spinal Block for Lower Limb Orthopedic Surgery
}

Wafaa Zaki AL- Morsy, Gihan Eissa Eliwa Zahran, Doha Mohamed Saad AL- Metwaly Salem*

Department of Anesthesia, Intensive Care, and Pain Management. Faculty of Medicine for Girls, Al-Azhar University

*Corresponding author: Doha Mohamed Saad AL- Metwaly Salem, Mobile: (+20)01009969627,

E-Mail: doha.salem1228@gmail.com

\begin{abstract}
Background: The effective relief of pain is of paramount importance for patients undergoing surgery.

Patient and methods: Sixty patients, aged 35 - 45 years, ASA I and II, scheduled for elective lower limb orthopedic surgery under spinal anesthesia were randomly divided into three equal groups, Control group: were given intrathecal $20 \mathrm{mg}(4 \mathrm{~mL})$ of $0.5 \%$ hyperbaric bupivacaine. Fentanyl group: were given $17.5 \mathrm{mg}$ (3.5 mL) of $0.5 \%$ hyperbaric bupivacaine with $25 \mu \mathrm{g}$ intrathecal fentanyl. Nalbuphine group: were given $17.5 \mathrm{mg}(3.5 \mathrm{~mL})$ of $0.5 \%$ hyperbaric bupivacaine with $0.8 \mathrm{mg}$ intrathecal preservative-free nalbuphine hydrochloride.

Results: There were no statistically significant differences between the three groups regarding the demographic data or HR. The decrease in MAP was significantly lower in the nalbuphine group when compared with fentanyl and control groups. The onset of complete motor and the sensory block was statistically significant rapid in the fentanyl group when compared with other groups. The duration of the motor and the sensory block was highly statistically significantly prolonged in the nalbuphine group when compared with other groups. Postoperative VAS showed a highly statistically significant difference between the three groups.

Conclusion: Nalbuphine $(0.8 \mathrm{mg})$ as intrathecal adjuvants to $0.5 \%$ hyperbaric bupivacaine increases the duration of sensory block, motor block, and effective analgesia, and decreases the incidence of intraoperative complication more efficiently than fentanyl in patients scheduled for elective lower limb orthopedic surgery under spinal anesthesia.
\end{abstract}

Keywords: Spinal anesthesia, bupivacaine hydrochloride, nalbuphine, fentanyl.

\section{INTRODUCTION}

The sub-arachnoid block has several advantages over general anesthesia as it is easy to perform, reduces stress response to surgery, and provides effective postoperative analgesia ${ }^{\mathbf{( 1 )}}$.

Various local anesthetics are available with different durations of action and different degrees of safety. Spinal anesthesia with only local anesthetics provides analgesia of short duration. For this reason, many intrathecal adjuvants are added to local anesthetics to prolong the effect of spinal anesthesia ${ }^{(2)}$.

Intrathecal administration of opioids as an adjuvant to local anesthetics was found to prolong the duration of postoperative analgesia, reduces local anesthetic requirements, and provides better analgesia, better hemodynamic stability and lesser side effects than the administration of an individual drug alone, because both drugs have different sites of action, as the local anesthetics produce its effects by acting at nerve axon while opioids act on opioid receptors at the spinal cord $^{(3)}$.

Fentanyl is highly lipid-soluble $\mu$ (mu) opioid receptor agonist, that improves the quality of sensory anesthesia and extends the duration of postoperative analgesia, this pure agonist effect is principally responsible for supraspinal and spinal analgesia along with the side effects like nausea, vomiting, pruritus, sedation, and respiratory depression. Nalbuphine, a synthetic opioid acts as a partial kappa receptor agonist and $\mu$ receptor antagonist ${ }^{(4)}$.

This mixed agonist-antagonist effect produces analgesia and sedation through agonism at the kappa receptors and lesser side effects when compared to intrathecal fentanyl through antagonism at the mu receptors $(5,6)$.

\section{AIM OF THE WORK}

This study was conducted to compare the effect of adding intrathecal nalbuphine hydrochloride versus intrathecal fentanyl on the characteristics of hyperbaric bupivacaine spinal block for lower limb orthopedic surgery.

\section{PATIENTS AND METHODS}

This prospective randomized double-blinded and placebo-controlled study was conducted at $\mathrm{Al}-$ Zahraa University hospital on sixty (60) adult patients scheduled for elective lower limb orthopedic surgery under spinal anesthesia, which started from January 2020 to April 2020.After obtaining approval of AlAzhar University medical research ethics committee and written informed consent from all patients in the study. Age group between 35 to 45 years of both genders, with weight $50-90 \mathrm{~kg}$, and height $>150 \mathrm{~cm}$ belonging to American Society of Anesthesiologists physical status I and II (ASA I and II) were enrolled in this study.

While patients with a history of an allergic reaction to local anesthetic drugs, contraindication for 
spinal anesthesia, bleeding disorders, pre-existing neurologic or spinal disease, spinal cord deformity, infection at the site of injection, renal or hepatic insufficiency, unstable cardiopulmonary status, ASA physical status more than II, and pregnant women were excluded from the study. Patients were randomly assigned by computer-generated random numbers and sealed opaque envelopes into three groups: Control (C group), fentanyl (f group), and nalbuphine ( $\mathrm{N}$ group) with 20 patients for each group.

All patients were checked 24 hours before surgery to fulfill the inclusion criteria of the study through history taking, clinical examination, for reviewing the results of routine investigations including complete blood picture, coagulation profile, liver function tests, renal function tests, serum electrolytes, and chest x-ray, and for assessment of ASA physical status of the patients. During the preoperative assessment, all patients were instructed to use a visual analog scale (VAS) for postoperative pain assessment. All patients received one tablet of midazolam $(0.2 \mathrm{mg} / \mathrm{kg})$ orally the night before surgery and instructed to be NPO for 6 hours preoperatively for solid food and two hours for clear fluids. On arrival at the operating theater, a peripheral intravenous line was secured with $18 \mathrm{G}$ intravenous cannula and a preload by lactated Ringer's solution infusion $(10-15 \mathrm{ml} / \mathrm{kg}$ ) was started. ASA standard monitoring by Drager (Vista 120) monitor manufactured by (Drager medical system, Inc. USA) was used for monitoring of all patients, and monitoring devices including electrocardiograph (ECG), non-invasive arterial blood pressure (NIBP) and pulse oximetry were connected to the patients and the baseline values were recorded.

While the patients were in sitting position and under complete aseptic conditions, the spinal block was performed at L3-L4 or L4-L5 level through midline approach with the study drug solution, which was administered intrathecally as per group allocation after confirmation of cerebrospinal fluid free flow without barbotage through a 25-gauge spinal needle and injection was over 15 second. Patients of control $(\mathrm{C}$ group), were given intrathecal $20 \mathrm{mg}(4 \mathrm{~mL})$ of $0.5 \%$ hyperbaric bupivacaine. While patients of the fentanyl group (F group) were given $17.5 \mathrm{mg}(3.5 \mathrm{~mL})$ of $0.5 \%$ hyperbaric bupivacaine with $25 \mu \mathrm{g}$ intrathecal fentanyl making intrathecal drug volume $4 \mathrm{~mL}$ for each patient. And those of nalbuphine ( $\mathrm{N}$ group) were given $17.5 \mathrm{mg}$ $(3.5 \mathrm{~mL})$ of $0.5 \%$ hyperbaric bupivacaine with $0.8 \mathrm{mg}$ preservative-free nalbuphine hydrochloride (the dose of intrathecal nalbuphine was measured using insulin syringe from ampoule containing preservative-free nalbuphine hydrochloride $20 \mathrm{mg}$ in $1 \mathrm{ml}$ ), $0.9 \%$ normal saline was added to make intrathecal drug volume 4 $\mathrm{mL}$ for each patient. Patients were placed in supine with a $10^{\circ}$ Trendelenburg position immediately after the block, and the sensory block was assessed according to loss of temperature sensation with ice pads.

All patients were received supplemental oxygen through a nasal cannula at a rate of $3 \mathrm{~L} / \mathrm{min}$. Warmed IV fluids and/or blood were administered according to the hemodynamic parameters and blood loss. Boluses of ephedrine (5mg per dose) and atropine $(0.01 \mathrm{mg} / \mathrm{kg}$ per dose) were used to correct oversympatholysis and to maintain the change in hemodynamics within $20 \%$ of baseline. Ondansetron (10mg per dose) was used to treat nausea and vomiting, pethidine (25mg per dose) was used to treat shivering and diphenhydramine (25mg per dose) was used to treat pruritus, but if the pruritus was still persistent or sever, intravenous infusion of naloxone at $1 \mu \mathrm{g} / \mathrm{kg} / \mathrm{hr}$ was used.

Assessment parameters included demographic data (age, sex, weight, height, ASA, type and duration of surgery), hemodynamic measurements including heart rate (beat $/ \mathrm{min})$, systolic, diastolic and mean arterial blood pressures $(\mathrm{mmHg})$ which were recorded preoperatively, 3 minutes after spinal anesthesia and every 10 minutes till the end of surgery, onset of complete motor block which was defined as the time taken after intrathecal injection to achieve Bromage scale III, [grading for motor block was done according to the modified Bromage motor scale $(0=$ full movement, I = loss of hip flexion, II = loss of knee flexion, III $=$ loss of planter flexion extention)], duration of complete motor block which was defined as the time required for grade III motor block to reach grade 0 in Bromage scale, onset of complete sensory block which was the time after intrathecal injection required to loss of temperature sensation with ice pads, duration of complete sensory block which was the time interval from the subarachnoid block to the first sensation of pain (VAS $>0$ ), pain intensity using visual analogue scale VAS scores which was assessed immediately after intrathecal injection and every one hour up to seven hours after intrathecal injection (the patients were asked to indicate on a $10 \mathrm{~cm}$ line at the point that was corresponding to the degree of pain that the patient experienced, ranging from no pain at 0 to maximum pain at 10 point), intraoperative complications including nausea, vomiting, shivering, hypotension, bradycardia and pruritus and duration of effective analgesia which was the time interval from the subarachnoid block to the first analgesic intervention (VAS >3) where intravenous 30mg ketorolac was administrated and can be repeated after 6 hours if needed.

If the patient was still complaining of pain or the VAS was still greater than 3 after 20 minutes from ketorolac injection, the patient was given intravenous pethidine in a dose of $0.5 \mathrm{mg} / \mathrm{kg}$.

Ethical approval and written informed consent: 
Approval of the study was obtained from the Al-Azhar University academic and ethical committee. Every patient signed informed written consent for the acceptance of the operation.

\section{Sample size justification:}

MedCalc® version 12.3.0.0 program "Ostend, Belgium" was used for calculations of sample size, statistical calculator based on $95 \%$ confidence interval and power of the study $80 \%$ with $\alpha$ error $5 \%$, According to a previous study ${ }^{(7)}$, showed that the duration of postoperative complete and effective analgesia was highly significantly longer in $\mathrm{BN}$ group than the corresponding durations in $\mathrm{BF}$ group $(\mathrm{P}<0.001$ and 0.002 , respectively). The postoperative 24-h analgesic doses of ketorolac and pethidine were less in the $\mathrm{BN}$ group than in the $\mathrm{BF}$ group $(\mathrm{P}=0.03,0.005$, respectively). So it can be relied upon in this study, based on this assumption, the sample size was calculated according to these values produced a minimal samples size of 57 cases were enough to find such a difference. Assuming a drop-out ratio of 5\%, the sample size will be 60 cases, subdivided into three groups; Group BN: 20; Group BF: 20 and Group C: 20

\section{Statistical analysis}

The collected data were analyzed using the statistical package for social sciences, version 20.0
(SPSS Inc., Chicago, Illinois, USA). Quantitative data were expressed as mean \pm standard deviation (SD) and qualitative data were expressed as frequency and percentage.

The following tests were done: Independentsamples t-test of significance was used when comparing between two means, A one-way analysis of variance (ANOVA) when comparing between more than two means with parametric data, Kruskal Wallis test for multiple-group comparisons in non-parametric data with non-parametric data, Mann Whitney z test for two-group comparisons in non-parametric data, Chisquare $\left(\mathrm{x}^{2}\right)$ test of significance was used to compare proportions between qualitative parameters, The confidence interval was set to $95 \%$ and the margin of error accepted was set to $5 \%$. So, the p-value was considered significant as the following: Probability (Pvalue) $\mathrm{P}$-value $\leq 0.05$ was considered significant, $\mathrm{P}$ value $\leq 0.001$ was considered as highly significant and $\mathrm{P}$-value $>0.05$ was considered insignificant.

\section{RESULTS}

The variables in demographic data did not show a statistically significant difference between the three groups concerning age, weight, height, sex, ASA, type of surgery and duration of surgery as shown in Table (1).

Table (1): Demographic data in the study groups.

\begin{tabular}{|c|c|c|c|c|c|c|}
\hline Demographic data & $\begin{array}{l}\text { Nalbuphine } \\
\text { Group }(n=20)\end{array}$ & $\begin{array}{c}\text { Fentanyl } \\
\text { Group }(\mathbf{n}=20)\end{array}$ & $\begin{array}{c}\text { Control } \\
\text { Group } n=20)\end{array}$ & $\begin{array}{l}\text { Test } \\
\text { value }\end{array}$ & p-value & Test \\
\hline Age (years) Mean \pm SD & $41.65 \pm 5.21$ & $41.30 \pm 4.09$ & $41.75 \pm 5.41$ & $0.046^{\bullet}$ & 0.955 & \multirow{3}{*}{$\begin{array}{c}\text { One Way } \\
\text { ANOVA } \\
\text { Test }\end{array}$} \\
\hline Weight (kg) Mean \pm SD & $71.05 \pm 5.37$ & $70.55 \pm 5.26$ & $70.45 \pm 6.36$ & $0.064 \bullet$ & 0.938 & \\
\hline Height (cm) Mean \pm SD & $165.25 \pm 3.84$ & $165.35 \pm 3.27$ & $165.25 \pm 3.52$ & $0.005 \bullet$ & 0.995 & \\
\hline \multicolumn{6}{|l|}{ Sex } & \multirow{17}{*}{$\begin{array}{c}\text { Chi-square } \\
\text { test }\end{array}$} \\
\hline Female & $9(45.0 \%)$ & $8(40.0 \%)$ & $9(45.0 \%)$ & \multirow{2}{*}{$0.136^{*}$} & \multirow{2}{*}{0.934} & \\
\hline Male & $11(55.0 \%)$ & $12(60.0 \%)$ & $11(55.0 \%)$ & & & \\
\hline ASA & & & & & & \\
\hline $\mathrm{I}$ & $15(75.0 \%)$ & $13(65.0 \%)$ & $15(75.0 \%)$ & \multirow{2}{*}{$0.657 *$} & \multirow{2}{*}{0.720} & \\
\hline II & $5(25.0 \%)$ & $7(35.0 \%)$ & $5(25.0 \%)$ & & & \\
\hline \multicolumn{6}{|l|}{ Type of surgery } & \\
\hline Fixation by plate and screw & $5(25.0 \%)$ & $2(10.0 \%)$ & $0(0.0 \%)$ & \multirow{10}{*}{$18.358^{*}$} & \multirow{10}{*}{0.432} & \\
\hline $\mathrm{k}$ wire & $2(10.0 \%)$ & $2(10.0 \%)$ & $3(15.0 \%)$ & & & \\
\hline knee arthroscopy & $3(15.0 \%)$ & $5(25.0 \%)$ & $3(15.0 \%)$ & & & \\
\hline Implant removal & $2(10.0 \%)$ & $1(5.0 \%)$ & $5(25.0 \%)$ & & & \\
\hline Dynamic heavy screw & $2(10.0 \%)$ & $3(15.0 \%)$ & $4(20.0 \%)$ & & & \\
\hline Medial minesectomy & $1(5.0 \%)$ & $3(15.0 \%)$ & $2(10.0 \%)$ & & & \\
\hline Debridement & $0(0.0 \%)$ & $2(10.0 \%)$ & $2(10.0 \%)$ & & & \\
\hline Total knee replacement & $2(10.0 \%)$ & $0(0.0 \%)$ & $1(5.0 \%)$ & & & \\
\hline External fixation & $1(5.0 \%)$ & $1(5.0 \%)$ & $0(0.0 \%)$ & & & \\
\hline Total hip replacement & $2(10.0 \%)$ & $1(5.0 \%)$ & $0(0.0 \%)$ & & & \\
\hline $\begin{array}{l}\text { Duration of surgery (min) } \\
\text { Mean } \pm \text { SD }\end{array}$ & $93.50 \pm 12.09$ & $89.00 \pm 11.65$ & $88.00 \pm 8.34$ & 1.482\# & 0.582 & T-test \\
\hline
\end{tabular}

- One way ANOVA test. * Chi-square test. \# Independent T-test, P-value >0.05 NS.

As regard to heart rate (beat/min) there was no statistically significant difference between the three groups as shown in (Table 2, Figure 1).

Table (2): Comparison between studied groups according to heart rate (beat $/ \mathrm{min})$. 


\begin{tabular}{|c|c|c|c|c|c|}
\hline \multirow{2}{*}{ Heart rate(b/min) } & Nalbuphine group & Fentanyl group & Control group & \multirow{2}{*}{ Test value } & P-value \\
\cline { 2 - 5 } & Mean \pm SD & Mean \pm SD & Mean \pm SD & & \\
\hline Base line & $84.30 \pm 5.73$ & $83.55 \pm 9.90$ & $81.60 \pm 12.93$ & 1.020 & 0.112 \\
\hline After 3 min & $83.75 \pm 4.38$ & $82.95 \pm 9.50$ & $81.60 \pm 12.20$ & 0.130 & 0.214 \\
\hline After 10 min & $81.35 \pm 4.60$ & $82.30 \pm 9.62$ & $79.80 \pm 10.11$ & 0.841 & 0.096 \\
\hline After 20 min & $79.30 \pm 4.78$ & $79.15 \pm 9.26$ & $77.90 \pm 10.20$ & 0.974 & 0.171 \\
\hline After 30 min & $75.55 \pm 3.69$ & $77.50 \pm 10.64$ & $76.05 \pm 10.63$ & 1.074 & 0.198 \\
\hline After 40 min & $72.65 \pm 4.21$ & $75.40 \pm 12.30$ & $73.70 \pm 11.25$ & 0.798 & 0.199 \\
\hline After 50 min & $73.10 \pm 4.54$ & $74.20 \pm 12.30$ & $71.55 \pm 12.39$ & 0.700 & 0.126 \\
\hline After 60 min & $72.80 \pm 3.96$ & $73.50 \pm 12.14$ & $71.40 \pm 13.07$ & 0.403 & 0.253 \\
\hline After 70 min & $74.15 \pm 3.53$ & $74.65 \pm 10.92$ & $72.20 \pm 12.56$ & 0.324 & 0.658 \\
\hline After 80 min & $72.90 \pm 3.21$ & $77.16 \pm 9.66$ & $73.94 \pm 11.31$ & 0.273 & 0.263 \\
\hline After 90 min & $73.75 \pm 2.67$ & $72.82 \pm 8.92$ & $72.00 \pm 7.85$ & 0.372 & 0.197 \\
\hline After 100 min & $72.00 \pm 3.70$ & $73.83 \pm 9.99$ & $71.00 \pm 0.00$ & 0.408 & 0.119 \\
\hline After 110 min & $71.14 \pm 2.27$ & $72.00 \pm 0.00$ & $70.84 \pm 10.47$ & 0.329 & 0.684 \\
\hline After 120 min & $71.80 \pm 2.49$ & $71.00 \pm 0.00$ & $72.39 \pm 8.91$ & 0.272 & 0.729 \\
& & & & & \\
\hline
\end{tabular}

t-Independent Sample t-test.

P-value $>0.05$ NS.

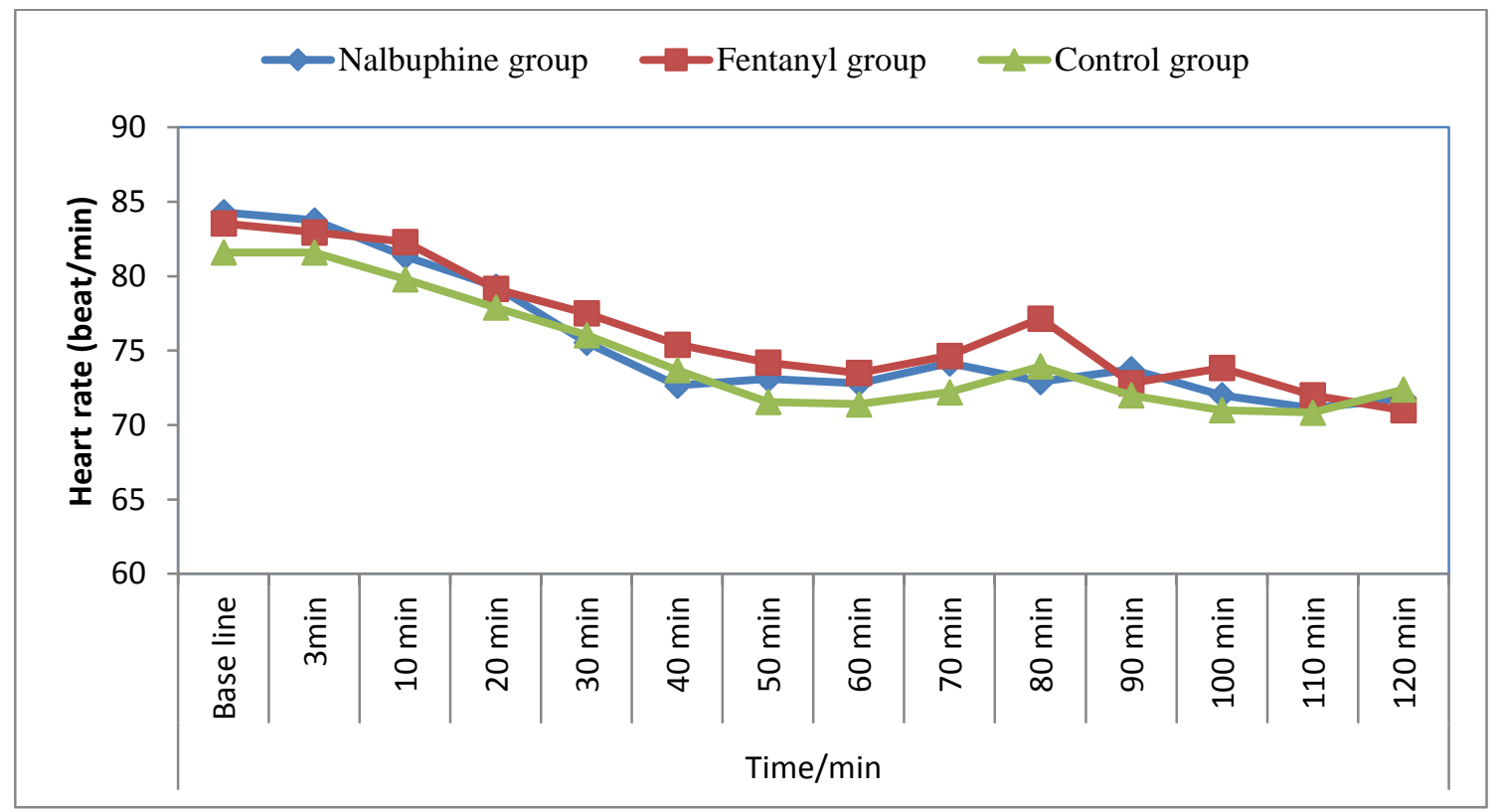

Fig. (1): Comparison between studied groups according to heart rate (beat/min).

As regard to mean arterial blood pressure $(\mathrm{mmHg})$, baseline values showed no statistically significant difference between the three groups (P-value $>0.05$ ). But in all the subsequent recordings after intrathecal injection, there was a statistically significant difference between the three groups ( $\mathrm{P}$-value $<0.05)$, as the decrease in MAP, was significantly lower in nalbuphine group when compared with fentanyl and control group as shown in (Table 3, Figure 2).

Table (3): Mean arterial pressure in the studied groups. 


\begin{tabular}{|l|l|c|c|c|c|c|}
\hline \multicolumn{2}{|c|}{ MAP $(\mathbf{m m H g})$} & $\begin{array}{c}\text { Nalbuphine group } \\
(\mathbf{n}=\mathbf{2 0})\end{array}$ & $\begin{array}{c}\text { Fentanyl group } \\
(\mathbf{n = 2 0 )}\end{array}$ & $\begin{array}{c}\text { Control group } \\
(\mathbf{n}=\mathbf{2 0})\end{array}$ & $\begin{array}{c}\text { Test } \\
\text { value• }\end{array}$ & P-value \\
\hline Base line & Mean \pm SD & $91.90 \pm 7.46$ & $93.20 \pm 10.04$ & $95.65 \pm 9.60$ & 0.875 & 0.423 \\
\hline After3min & Mean \pm SD & $87.45 \pm 10.44$ & $87.95 \pm 7.65$ & $89.25 \pm 7.22$ & 1.041 & 0.320 \\
\hline After10 min & Mean \pm SD & $84.90 \pm 10.69$ & $81.80 \pm 9.05$ & $79.05 \pm 7.78$ & 3.414 & $0.026^{*}$ \\
\hline After20 min & Mean \pm SD & $86.15 \pm 9.48$ & $80.80 \pm 8.14$ & $78.00 \pm 12.57$ & 2.749 & $0.023^{*}$ \\
\hline After30 min & Mean \pm SD & $87.35 \pm 11.30$ & $83.90 \pm 15.74$ & $79.25 \pm 14.53$ & 3.699 & $0.019^{*}$ \\
\hline After40 min & Mean \pm SD & $86.25 \pm 9.47$ & $82.05 \pm 10.87$ & $79.55 \pm 11.53$ & 3.375 & $0.018^{*}$ \\
\hline After50 min & Mean \pm SD & $85.60 \pm 9.76$ & $82.45 \pm 8.33$ & $79.70 \pm 9.25$ & 2.923 & $0.018^{*}$ \\
\hline After60 min & Mean \pm SD & $87.20 \pm 9.88$ & $83.30 \pm 11.77$ & $82.05 \pm 5.79$ & 2.414 & $0.019^{*}$ \\
\hline After70 min & Mean \pm SD & $87.45 \pm 7.68$ & $84.90 \pm 11.00$ & $81.75 \pm 4.42$ & 4.670 & $0.020^{*}$ \\
\hline After80 min & Mean \pm SD & $87.45 \pm 8.17$ & $83.74 \pm 9.41$ & $80.56 \pm 5.32$ & 3.589 & $0.021^{*}$ \\
\hline After90 min & Mean \pm SD & $86.00 \pm 9.03$ & $82.82 \pm 7.53$ & $79.43 \pm 4.35$ & 2.399 & $0.019^{*}$ \\
\hline After100 min & Mean \pm SD & $88.77 \pm 9.31$ & $85.00 \pm 7.69$ & $82.18 \pm 5.84$ & 3.864 & $0.021^{*}$ \\
\hline After110 min & Mean \pm SD & $90.29 \pm 8.54$ & $87.18 \pm 4.68$ & $84.18 \pm 6.44$ & 2.755 & $0.030^{*}$ \\
\hline After120 min & Mean \pm SD & $92.60 \pm 7.83$ & $89.14 \pm 4.76$ & $85.43 \pm 4.35$ & 3.356 & $0.031^{*}$ \\
\hline
\end{tabular}

-One Way ANOVA test

p-value $>0.05 \mathrm{NS} ;{ }^{*}$ p-value $<0.05 \mathrm{~S}$

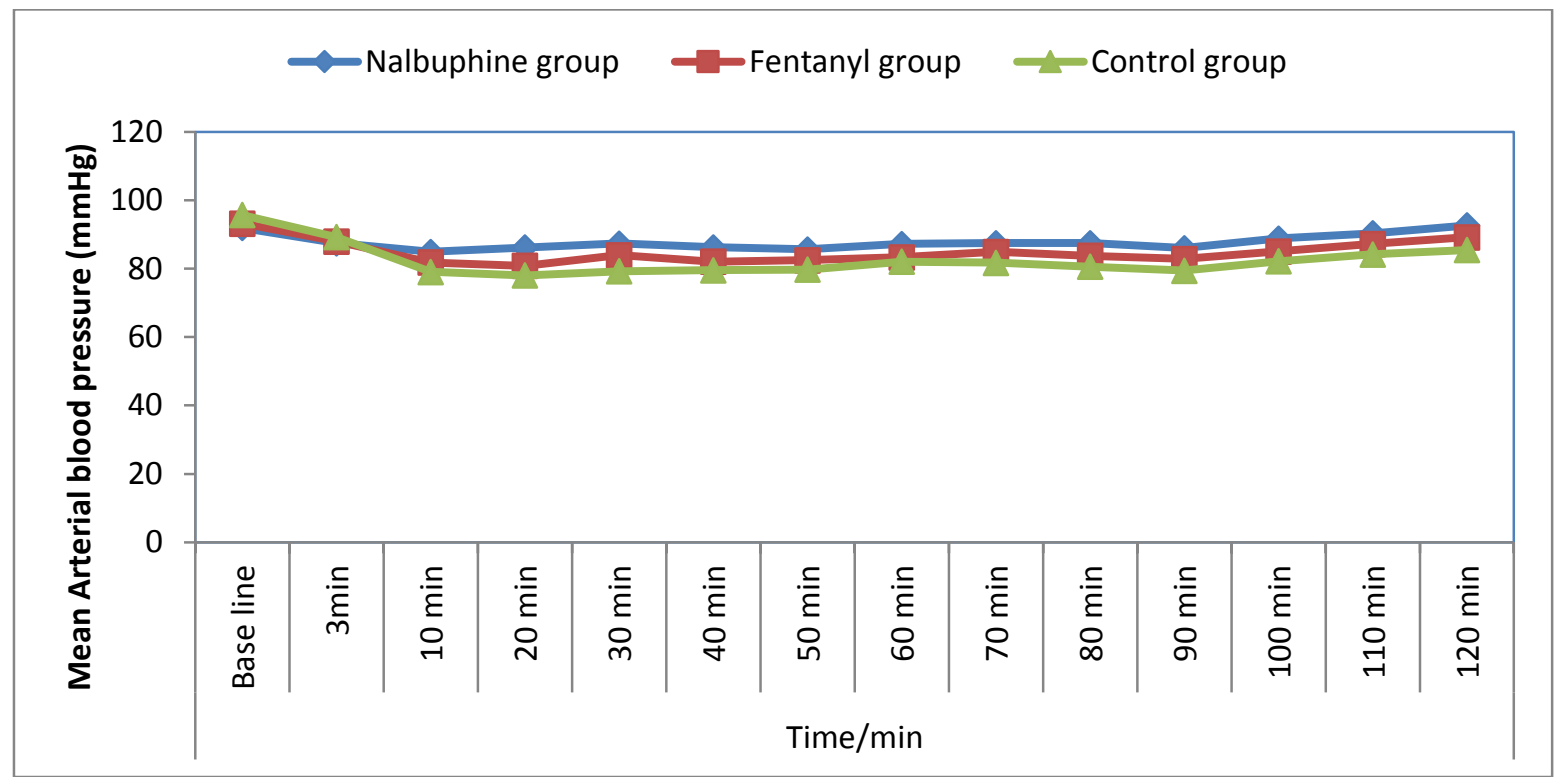

Fig. (2): Comparison between groups according to mean arterial blood pressure (mmHg).

As regards the onset of complete motor block, there was a statistically significant difference between the three groups, as the onset was rapid in the fentanyl group when compared with the nalbuphine and control group as shown in (Table 4). As regards the onset of complete sensory block, there was a statistically significant difference between the three groups as the onset was rapid in the fentanyl group when compared with the nalbuphine and control group as shown in (Table 4). As regards the duration of the motor block, there was a highly statistically significant difference between the three groups as the duration was prolonged in the nalbuphine group when compared with the fentanyl and control group as shown in (table 4). As regards the duration of sensory block, there was a highly statistically significant difference between the three groups, as the duration was prolonged in the nalbuphine group when compared with the fentanyl and control group as shown in (Table 4).

Table (4): Comparison between studied groups according to onset and duration of complete motor and sensory block. 


\begin{tabular}{|l|c|c|c|c|c|c|}
\hline \multicolumn{2}{|l|}{} & $\begin{array}{c}\text { Nalbuphine group } \\
(\mathbf{n = 2 0})\end{array}$ & $\begin{array}{c}\text { Fentanyl group } \\
(\mathbf{n = 2 0})\end{array}$ & $\begin{array}{c}\text { Control group } \\
(\mathbf{n = 2 0})\end{array}$ & $\begin{array}{c}\text { Test } \\
\text { value• }\end{array}$ & P-value \\
\hline $\begin{array}{l}\text { Onset of complete motor } \\
\text { block ( sec post spinal) }\end{array}$ & Mean \pm SD & $57.50 \pm 18.53$ & $51.00 \pm 11.31$ & $62.00 \pm 15.08$ & 2.831 & $0.022^{*}$ \\
\hline $\begin{array}{l}\text { Onset of complete sensory } \\
\text { block ( sec post spinal) }\end{array}$ & Mean \pm SD & $35.00 \pm 13.76$ & $30.75 \pm 9.07$ & $40.00 \pm 7.54$ & 3.514 & $0.014^{*}$ \\
\hline $\begin{array}{l}\text { Duration of motor block } \\
\text { (hrs post spinal) }\end{array}$ & Mean \pm SD & $4.61 \pm 0.45$ & $2.84 \pm 0.37$ & $2.15 \pm 0.15$ & 261.260 & $0.000^{* *}$ \\
\hline $\begin{array}{l}\text { Duration of sensory block } \\
\text { (hrs post spinal) }\end{array}$ & Mean \pm SD & $5.70 \pm 0.47$ & $3.21 \pm 0.14$ & $2.65 \pm 0.36$ & 427.587 & $0.000^{* *}$ \\
\hline
\end{tabular}

•One Way ANOVA test; *p-value <0.05 S; **p-value <0.001 HS

As regards postoperative VAS there was no statistically significant difference between the three groups in the $1^{\text {st }}$ hour postoperative while from the $2^{\text {nd }}$ to the $7^{\text {th }}$ postoperative hour, there was a statistically highly significant difference between the three groups in VAS score. Except at $6 \mathrm{hr}$ postoperative, there was a statistically significant difference between the three groups as shown in (Table 5, Figure 7).

Table (5): Comparison between groups according to the VAS score.

\begin{tabular}{|l|l|c|c|c|c|c|}
\multicolumn{2}{|c|}{ VAS score } & $\begin{array}{c}\text { Nalbuphine group } \\
(\mathbf{n = 2 0 )}\end{array}$ & $\begin{array}{c}\text { Fentanyl group } \\
(\mathbf{n = 2 0 )}\end{array}$ & $\begin{array}{c}\text { Control group } \\
(\mathbf{n = 2 0})\end{array}$ & $\begin{array}{c}\text { Test value } \\
+\end{array}$ & P-value \\
\hline $1 \mathrm{H}$ & Median (IQR) & $0(0-0)$ & $0(0-0)$ & $0(0-0)$ & 0.000 & 1.000 \\
\hline $2 \mathrm{H}$ & Median (IQR) & $0(0-0)$ & $1(0-0)$ & $2(1-2)$ & 59.000 & $0.000^{* *}$ \\
\hline $3 \mathrm{H}$ & Median (IQR) & $1(1-1)$ & $2(1-2)$ & $3(3-3)$ & 59.000 & $0.000^{* *}$ \\
\hline $4 \mathrm{H}$ & Median (IQR) & $1(1-1)$ & $2(1-1)$ & $3(3-3)$ & 58.344 & $0.000^{* * *}$ \\
\hline $5 \mathrm{H}$ & Median (IQR) & $1(1-1)$ & $1(1-2)$ & $2(2-2)$ & 39.508 & $0.000^{* *}$ \\
\hline $6 \mathrm{H}$ & Median (IQR) & $1(2-3)$ & $2(2-2)$ & $3(2-3)$ & 12.739 & $0.002^{*}$ \\
\hline $7 \mathrm{H}$ & Median (IQR) & $1(1-3)$ & $2(2-3)$ & $3(3-3)$ & 13.079 & $0.001^{* *}$ \\
\hline
\end{tabular}

+ Kruskal Wallis test. p-value $>0.05 \mathrm{NS} ; *$ p-value $<0.05 \mathrm{~S} ; * *$ p-value $<0.001 \mathrm{HS}$

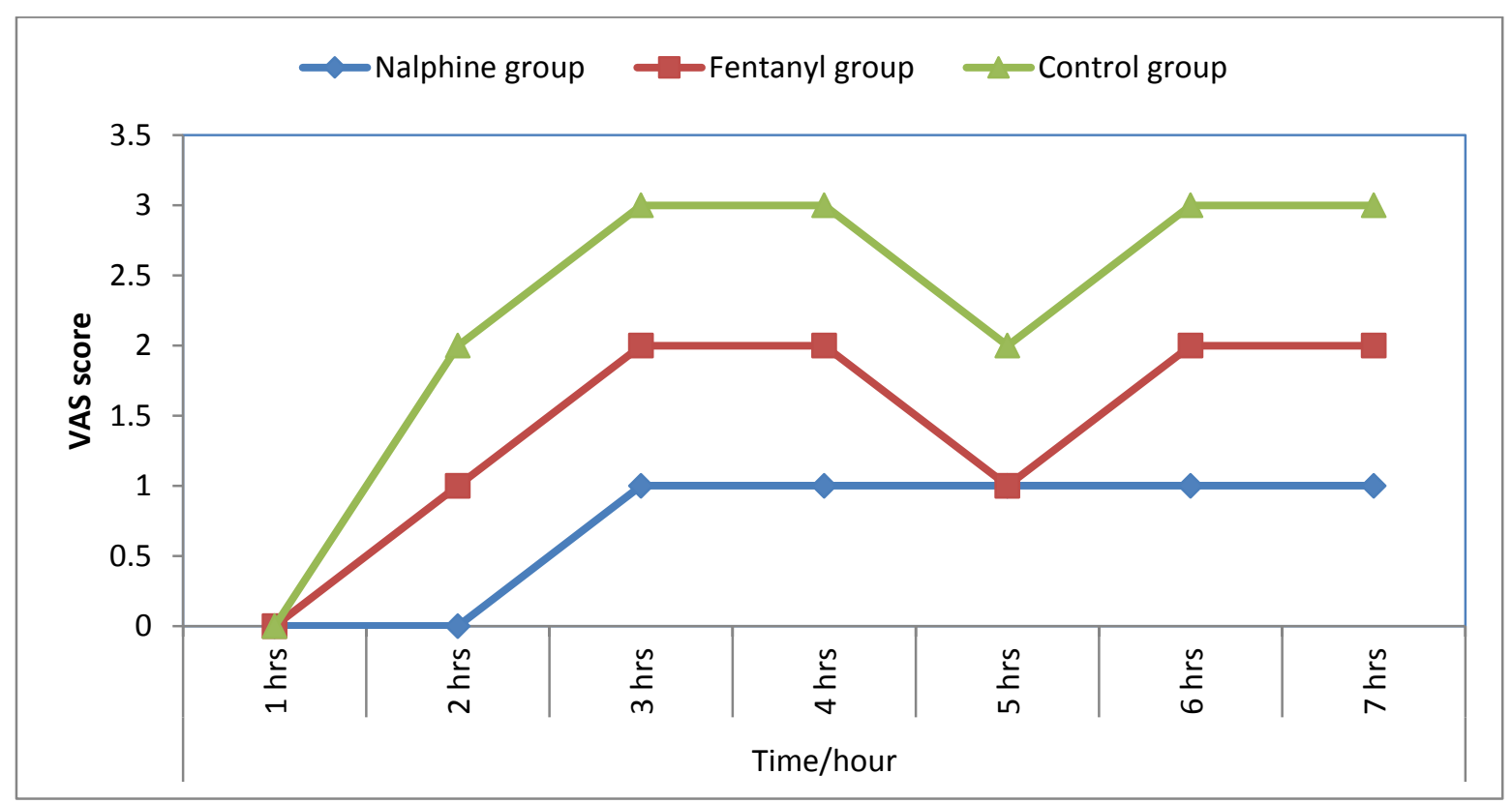

Fig. (7): Comparison between studied groups according to the VAS score.

As regards the time to the first request of analgesia after intrathecal injection, there was a highly statistically significant difference between the three groups, as the duration was prolonged in the nalbuphine group when compared with fentanyl and control group as shown in (Table 6, Figure 8).

Table (6): Comparison between three groups according to the first requirement of analgesia (hours). 


\begin{tabular}{|l|c|c|c|c|c|c|}
\hline \multicolumn{2}{|c|}{} & Nalbuphine group & Fentanyl group & $\begin{array}{c}\text { Control } \\
\text { group }\end{array}$ & $\begin{array}{c}\text { Test } \\
\text { value }\end{array}$ & $\begin{array}{c}\text { P- } \\
\text { value }\end{array}$ \\
\cline { 2 - 5 } & No. $=\mathbf{2 0}$ & No. $=\mathbf{2 0}$ & No. $=\mathbf{2 0}$ & \\
\hline $\begin{array}{l}\text { First requirement } \\
\text { of analgesia (hrs) }\end{array}$ & Mean \pm SD & $6.70 \pm 0.47$ & $3.79 \pm 0.33$ & $2.76 \pm 0.34$ & $561.938 \bullet$ & 0.000 \\
\hline
\end{tabular}

- One Way ANOVA test. (p-value < $0.001 \mathrm{HS}$ ).

As regards intraoperative complications, the results of the current study showed that there was a statistically significant low incidence in the occurrence of hypotension, bradycardia, and shivering in the nalbuphine group when compared with fentanyl and control group. But there was no statistically significant difference between the three groups in the occurrence of pruritus. No occurrence of nausea and vomiting in any group as shown in (Table 7, Figure 9).

Table (7): Comparison between studied groups according to intraoperative complications.

\begin{tabular}{|l|c|c|c|c|c|c|c|c|}
\hline \multirow{2}{*}{$\begin{array}{l}\text { Intra operative } \\
\text { complications }\end{array}$} & \multicolumn{2}{|c|}{ Nalbuphine group } & \multicolumn{2}{|c|}{ Fentanyl group } & \multicolumn{2}{c|}{ Control group } & Test & \multirow{2}{*}{ P-value } \\
\cline { 2 - 8 } value* $^{*}$ & No. & $\%$ & No. & $\%$ & No. & $\%$ & \\
\hline Hypotension & 3 & $15.0 \%$ & 8 & $40.0 \%$ & 13 & $65.0 \%$ & 6.192 & $0.032^{*}$ \\
Bradycardia & 0 & $0.0 \%$ & 2 & $10.0 \%$ & 3 & $15.0 \%$ & 2.381 & $0.032^{*}$ \\
Shivering & 1 & $5.0 \%$ & 4 & $20.0 \%$ & 7 & $35.0 \%$ & 5.327 & $0.029 *$ \\
Pruritus & 1 & $5.0 \%$ & 2 & $10.0 \%$ & 3 & $15.0 \%$ & 1.682 & 0.621 \\
Vomiting & 0 & $0.0 \%$ & 0 & $0.0 \%$ & 0 & $0.0 \%$ & 0.000 & 1.000 \\
Nausea & 0 & $0.0 \%$ & 0 & $0.0 \%$ & 0 & $0.0 \%$ & 0.000 & 1.000 \\
\hline
\end{tabular}

*Chi-square test.

p-value $>0.05 \mathrm{NS}$; *p-value $<0.05 \mathrm{~S}$;

\section{DISCUSSION}

The present study investigated the effect of adding intrathecal nalbuphine hydrochloride versus intrathecal fentanyl on the characteristics of hyperbaric bupivacaine spinal block for lower limb orthopedic surgery. As regards HR, the results of the current study showed that there was no statistically significant difference among the three studied groups. In agreement with the results of the current study, Gupta et al. ${ }^{(8)}$. in their study on sixty-eight patients scheduled for lower limb orthopedic surgery under spinal anesthesia, showed that there was no statically significant difference between studied groups according to HR.

As regards mean arterial pressure (MAP), the results of the current study showed that there was no statistically significant difference between the three groups in the baseline values of MAP. But in all the subsequent recordings after intrathecal injection, MAP values showed a statistically significant difference between the three groups. As the decrease in MAP was significantly lower in the nalbuphine group when compared with fentanyl and control groups, which indicated that intrathecal nalbuphine caused hemodynamic stability and attenuated the occurrence of post-spinal hypotension.
As the results of the current work, a study done by Jyothi et al. (9), on hundred patients scheduled for lower abdominal and lower limb orthopedic surgery under spinal anesthesia, showed that the use of intrathecal nalbuphine hydrochloride along with bupivacaine caused no gross hemodynamic disturbances even with increasing the nalbuphine dose from 0.8 to $2.4 \mathrm{mg}$.

Also, Tiwari et al. ${ }^{(10)}$, in their study on seventy-five patients scheduled for elective lower abdominal, urological and lower limb orthopedic surgery under spinal anesthesia, found that the use of intrathecal nalbuphine hydrochloride along with bupivacaine caused hemodynamic stability.

Also, Mostafa et al. ${ }^{(11)}$, in their study on sixty patients undergoing transurethral resection of bladder tumor under spinal anesthesia, discovered that the use of nalbuphine hydrochloride along with bupivacaine caused hemodynamic stability.

In contrast, Gupta et al. ${ }^{(8)}$, reported that there was no statically significant difference between nalbuphine and fentanyl in the maintenance of blood pressure.

Also, Forster and Rosenberg ${ }^{(12)}$ in their study on hundred patients scheduled for elective total abdominal hysterectomy under spinal anesthesia, found that there was no statically significant difference between intrathecal nalbuphine and intrathecal fentanyl in the maintenance of blood pressure. 
As regards the onset of complete motor block, the results of the current study showed that the onset was statistically significant rapid in the fentanyl group when compared with the nalbuphine and control group.

Similar to the results of the current work, a study done by, Vashishth et al. ${ }^{(13)}$, on hundred and fifty patients scheduled for lower abdominal and lower limb surgeries under spinal anesthesia, showed that the use of intrathecal fentanyl as an adjuvant to hyperbaric bupivacaine has produced more rapid onset of the complete motor block than the use of intrathecal nalbuphine.

On the other hand Sharma et al. ${ }^{(1)}$, in their study on 60 patients scheduled for lower limb orthopedic surgery under spinal anesthesia, found that there was no significant difference in the onset of the complete motor block between nalbuphine and fentanyl groups. As regards the onset of complete sensory block, the results of the current study showed that there was a statistically significant rapid onset in the fentanyl group when compared with the nalbuphine and control group.

Like the results of the current study, Vashishth et al. ${ }^{(13)}$ in their study, found that the onset of complete sensory block is more rapid with intrathecal fentanyl than with intrathecal nalbuphine.

And, Venkata et al. ${ }^{(14)}$, in their study on eighty parturients scheduled for elective cesarean section under spinal anesthesia, found that there was significantly faster onset of the complete sensory block with intrathecal fentanyl as an adjuvant.

Also, Gurunath and Madhusudhana ${ }^{(15)}$ in their study on one hundred and twenty-four patients scheduled for lower abdominal and lower limb surgeries under spinal anesthesia, found that there was significantly faster onset of the complete sensory block with fentanyl as an adjuvant. On the other hand, Sharma et al. ${ }^{(1)}$, in their study, found that there was no significant difference in the onset of complete sensory blockade between nalbuphine and fentanyl groups. Also, Gomaa et al. ${ }^{(4)}$, in their study on sixty female patients scheduled for elective cesarean delivery under spinal anesthesia, found that there was no significant difference in the onset of complete sensory blockade between intrathecal nalbuphine and fentanyl groups.

As regards the duration of the motor block, the results of the current study showed that there was a highly statistically significant prolongation in the duration of motor block in the nalbuphine group when compared with the fentanyl and control group. Supporting the results of the current study, Sharma et al. ${ }^{(1)}$ in their study, found that there was a statistically highly significant prolongation in the duration of motor block in the nalbuphine group when compared with fentanyl and control group. Also, Tiwari et al. ${ }^{(10)}$ found that there was a statistically significant prolongation in the duration of motor block in the nalbuphine group when compared with the fentanyl and control group. And Mostafa et al. ${ }^{(11)}$ discovered that there was a statistically significant prolongation in the duration of motor block in the nalbuphine group when compared with the fentanyl and control group. In contrast, Vashishth et al. ${ }^{(13)}$ in their study, found that there was a statistically significant prolongation in the duration of motor block in the fentanyl group when compared with the nalbuphine and control group.

As regards the duration of complete sensory block, the results of the current study showed that there was a statistically highly significant prolongation in the duration of sensory block in the nalbuphine group when compared with the fentanyl and control group. In agreement with the results of the current study, Sharma et al. ${ }^{(1)}$ in their study, found that there was a statistically significant prolongation in the duration of sensory block in the nalbuphine group when compared with fentanyl and control group. Furthermore, Tiwari et al. ${ }^{(10)}$ found that there was a statistically significant prolongation in the duration of sensory block in the nalbuphine group when compared with the fentanyl and control group. Also, Mostafa et al. (11) discovered that there was a statistically significant prolongation in the duration of sensory block in the nalbuphine group when compared with the fentanyl and control group. In contrary to the results of the current study, the study done by Vashishth et al. (13) found that there was a statistically significant prolongation in the duration of sensory block in the fentanyl group when compared with nalbuphine and control group. Also, Bindra et al. ${ }^{(16)}$ in their study on a hundred and fifty parturients scheduled for cesarean section under spinal anesthesia, found that there was a statistically significant prolongation in the duration of sensory block in fentanyl group when compared with nalbuphine and control group. Furthermore, Naaz et al. ${ }^{(17)}$ in their study on ninety patients scheduled for lower limb orthopedic surgeries under spinal anesthesia, found that there was a statistically significant prolongation in the duration of sensory block in the fentanyl group when compared with nalbuphine and control group.

As regards postoperative VAS, the results of the current study showed that at 1 st postoperative hour, there was no statistically significant difference in VAS score between the three groups. From the 2 nd to the 7 th postoperative hour, there was a statistically highly significant 
difference between the three groups in the VAS score. Except at $6 \mathrm{hr}$ postoperative, there was a statistically significant difference between the three groups, as VAS scores were lower in the nalbuphine group when compared with the fentanyl and control group. As the results of the current work, the study done by Gupta et al. ${ }^{\left({ }^{8}\right)}$, showed that there was a statistically significant reduction in pain scores in the nalbuphine group when compared with the fentanyl group. Also, Jyothi et

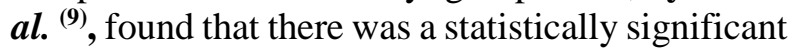
reduction in pain scores in the nalbuphine group when compared with the fentanyl group.

As regards the time to the first request of analgesia after intrathecal injection, the results of the current study showed that there was a highly statistically significant prolongation in the duration to the first request of analgesia in nalbuphine group when compared with fentanyl and control group. As the results of the current work, a study done by Sharma et al. (1) showed that there was a statistically significant prolongation in the time to the first requirement of analgesia in the nalbuphine group when compared with fentanyl and control groups. Also, Mostafa et al. ${ }^{(11)}$ in their study discovered that there was a statistically significant prolongation in the time to the first requirement of analgesia in the nalbuphine group when compared with fentanyl and control group. And, Tiwari $\boldsymbol{e t}$ al. (10) found that there was a statistically significant prolongation in the time to the first requirement of analgesia in the nalbuphine group when compared with fentanyl and control group. Similarly, Jyothi et $\boldsymbol{a l} .{ }^{(9)}$ in his study found that there was a statistically significant prolongation in the time to the first requirement of analgesia in the nalbuphine group which also was not affected by increasing the dose of intrathecal nalbuphine.

The results of the current study are against the results concluded by Gomaa et al. ${ }^{(4)}$ who found that there was no significant difference in the time to the first requirement of analgesia between nalbuphine and fentanyl groups.

As regards intraoperative complications, the results of the current study showed that there was a statistically significant difference between the three groups in the occurrence of hypotension, bradycardia, and shivering. But there was no statistically significant difference between the three groups in the occurrence of pruritus. In agreement with the results of the current study, Gurunath and Madhusudhana ${ }^{(15)}$, in their study found that there were minimal side effects in patients with intrathecal nalbuphine as an adjuvant than in patients with intrathecal fentanyl. Also, Sharma et al. (1) discovered that intrathecal nalbuphine $0.8 \mathrm{mg}$ provides good intraoperative and early postoperative analgesia, without any side effects. Besides, they found that increasing the dose of intrathecal nalbuphine did not increase the analgesic efficacy but can increase the side effects. Also, Sapate et al. ${ }^{(18)}$ in their study on forty patients scheduled for lower abdominal surgeries under spinal anesthesia, concluded that intrathecal nalbuphine provided a better quality of $\mathrm{SAB}$ as compared to bupivacaine alone and enhanced the postoperative analgesia without the development of any side effect in any of the patient. Also, Ahmed (7) in their study on eighty parturients scheduled for elective cesarean section under spinal anesthesia, found that the incidence of pruritus and shivering was significantly higher in the fentanyl group than in nalbuphine group.

\section{CONCLUSION}

This study concluded that Nalbuphine ( 0.8 $\mathrm{mg}$ ) as intrathecal adjuvants to $0.5 \%$ hyperbaric bupivacaine increases the duration of sensory block, motor block, decrease the incidence of intraoperative complications and the effective analgesia time more efficiently than fentanyl in patients scheduled for elective lower limb orthopedic surgery under subarachnoid block.

\section{REFERENCES}

1. Sharma DN, Padhy M, Kar M (2019): A randomized comparative study to assess the effect of intrathecal nalbuphine versus intrathecal fentanyl as an adjuvant to bupivacaine for lower limb orthopedic surgery. J Evolution Med Dent Sci., (12):830-834.

2. Mukherjee A, Pal A, Agrawal J (2011): Intrathecal nalbuphine as an adjunct to subarachnoid block: What is the most effective dose? Anesth Essays Res., 5(2):171-5.

3. Wilwerth M, Majcher JL, Van der Linden $P$ (2016): Spinal fentanyl vs. sufentanil for postoperative analgesia after C-section: a doubleblinded randomized trial. Acta Anaesthesiol Scand., 60(9):1306-13.

4. Gomaa HM, Mohamed NN, Zoheir HA (2014): A comparison between postoperative analgesia after intrathecal nalbuphine with bupivacaine and intrathecal fentanyl with bupivacaine after cesarean section. Egypt J Anaesth., 30(4):405-10.

5. Gunion MK, Marchionine AM, Anderson CTM (2004): Use of the mixed agonist-antagonist nalbuphine in opioid-based analgesia. Acute Pain, 6:29-39.

6. Culebras $\mathrm{X}$, Gaggero $\mathrm{G}$, Zatloukal $\mathrm{J}$ et al. (2000): Advantages of intrathecal nalbuphine, compared with intrathecal morphine, after cesarean delivery: an evaluation of postoperative analgesia and adverse effects. Anesth Analg., 91:601-5.

7. Ahmed FI (2019): Intrathecal nalbuphine versus fentanyl as an adjuvant to bupivacaine in spinal 
anesthesia for elective cesarean section: a randomized double-blind study. Res Opin Anesth Intensive Care, 6:112-8.

8. Gupta K, Rastogi B, Gupta PK et al. (2016): Intrathecal nalbuphine versus intrathecal fentanyl as an adjuvant to $0.5 \%$ hyperbaric bupivacaine for orthopedic surgery of lower limbs under subarachnoid block: A comparative evaluation. Indian J Pain, 30:90-5.

9. Jyothi B, Gowda S, Safiya I (2014): Department of Anesthesiology, Karnataka Institute of Medical Sciences, Hubli, Karnataka, India Journal of Pain, 1: $18-23$

10. Tiwari AK, Tomar GS, Agrawal J (2013): Intrathecal bupivacaine in comparison with a combination of nalbuphine and bupivacaine for subarachnoid block: a randomized prospective double-blind clinical study. Am J Ther., 6:592-5.

11. Mostafa MG, Mohamad MF, Farrag WS (2011): Which has a greater analgesic effect; Intrathecal nalbuphine or intrathecal tramadol. J Am Sci., 7:480-4.

12. Förster JG, Rosenberg PH (2003): Clinically useful adjuvants in regional anesthesia. Curr Opin Anaesthesiol., 16(5):477-86.

13. Vashishth T, Sharma G, Garg S et al. (2016): A comparative study intrathecal of nalbuphine and fentanyl with bupivacaine in spinal anesthesia for lower abdominal and lower limb surgeries. Nat $\mathrm{J}$ Med Dent Res., 4:93-100.

14. Venkata HG, Pasupuleti S, Pabba UG (2015): A randomized controlled prospective study comparing a low dose bupivacaine and fentanyl mixture to a conventional dose of hyperbaric bupivacaine for cesarean section. Saudi J Anaesth., 9(2):122-7.

15. Gurunath BB, Madhusudhana $R$ (2018): Postoperative analgesic efficacy of intrathecal fentanyl compared to nalbuphine with bupivacaine in spinal anesthesia for lower abdominal surgeries. Anesth Essays Res., 12(2):535-8.

16. Bindra TK, Kumar $P$, Jindal $G$ (2018): Postoperative analgesia with intrathecal nalbuphine versus intrathecal fentanyl in cesarean section: a double- blind randomized comparative study. Anesth Essays Res., 12(2):561-5.

17. Naaz S, Shukla U, Srivastava $S$ et al. (2017): U, A comparative study of analgesic effect of intrathecal nalbuphine and fentanyl as an adjuvant in lower limb orthopedic surgery. J Clin Diagn Res., 11(7):25-28.

18. Sapate M, Sahu P, Thatte WS et al. (2013): A randomized double-blind controlled study of the effects of adding nalbuphine to spinal bupivacaine for lower abdominal surgeries in elderly patients. Anaesth Pain Intensive Care, 17:145-8. 